\title{
EDITORIAL
}

\section{ROLE OF CARDIOVASCULAR INTERVENTION IN THE PRACTICE OF CARDIOLOGY}

Interventional cardiology is a latter day development in the practice of cardiology. It goes by many names, such as, percutaneous interventions, catheter-based therapies, transcatheter therapies among others. The vascular tree is entered through a "key" hole skin break from which the diseased part of the heart or the vascular tree is accessed. The main advantage of percutaneous intervention is to overcome some of the difficulties encountered in traditional surgical treatment of various diseases of the heart. These difficulties include the trauma to normal tissue and also to the treatment site, which is occasioned by the need to expose the diseased part and the subsequent surgical procedure. Cardiac surgical procedures need general anaesthesia and most require cardiopulmonary by-pass: a process, which is associated with considerable morbidity and some mortality. Recovery of the post surgical patient requires most frequently, high cost intensive care management, long stay in hospital and even longer stay at home before return to work.

For those conditions for which percutaneous intervention is possible, the trauma to normal tissues is minimal, most procedures are done under local anaesthesia and hospitalisation is usually from a few hours in hospital to one or two days unless there are complications or comorbidity. Cardiopulmonary by-pass and its attendant complications are avoided. Patients return to work early as associated surgical procedure morbidity is mostly absent. Money can be saved.

Catheter-based therapies were preceded by a period of several decades during which invasive diagnosis of heart disease became an intergral part of studying cardiac function and structure, complimenting the previously practised noninvasive diagnostic techniques. In humans, invasive diagnosis was ushered in 1929 when Werner Forsmann inserted a catheter through his own left antecubital vein to the right atrium(1). This was the beginning of the era of cardiac catheterisation, which through continuous refining and parallel progress in other fields such as X-ray imaging, was perfected to enable great understanding of normal and abnormal cardiovascular function and structure in living humans.

In 1953 Seldinger introduced the percutaneous technique of accessing the vascular tree(2). Other important historical landmarks among many, include Sones introduction of selective coronary arteriography in 1959(3).

With such extensive understanding of cardiovascular structure and haemodynamics and with public pressure to develop more tolerable therapies both for patient comfort and to overcome difficulties visiting traditional surgical therapies, it was inevitable that attempts would be made to extend the use of the catheter from a purely diagnostic tool to a therapeautic one as well.

Today, conditions treatable by percutaneous intervention include atheroscelerotic coronary and peripheral vascular disease, rheumatic mitral valve stenosis, congenital pulmonary valve stenosis, atrial septal defects, patent foramina ovale, patent ductus arteriosus, vascular malformations and aneurysms, among others. Percutaneous techniques are also frequently used today to stop intractable bleeding from viscera that may not be accessible to surgery or even obliterate vessels causing severe bleeding. Vessels feeding tumors such as hepatomas and colorectal carcinomas can be targeted and obliterated, thus stopping tumour growth.

Some historical perspective is necessary here since many aspects of cardiovascular intervention are yet to be covered in this journal. Charles Dotter is credited with the first significant attempt to open up atheroscelerotic obstructions (stenosis) of the vascular system. He devised a method of using progressively increasing diameter catheters, passed through stenosed superficial femoral arteries over a thin guide wire to open up the stenosis. This was the first intravascular angioplasty(4). Due to trauma at the access point and severe plaque disruption resulting in complications, the procedure did not gain widespread acceptance.

Modern coronary angioplasty, also called percutaneous transluminal coronary angioplasty (PTCA), was introduced by Andreas Gruentzig in 1977. He designed a catheter, tipped with a small balloon, which could be introduced uninflated, percutaneously, deployed astride the stenosed segment and then inflated with controlled pressure. On deflation and withdrawal of the balloon, a new lumen in the area of stenosis would be created. He performed the first case of human coronary balloon angioplasty in Zurich, Switzerland in September 1977(5). In 1987 coronary stents were introduced through the work of Urlich Sigwart. The purpose was to deal with acute closure of the artery at the time of balloon angioplasty, a complication that can result in myocardial infarction or even death during the procedure if not adequately treated. The stent would also address the troublesome problem of restenosis, which sometimes occurs later after the procedure(6). In Kenya, we performed the first PTCA in October 1997. This also happens to be the first PTCA done purely by local cardiologists in Africa south of the Sahara and outside South Africa. PTCA/Stenting is now available routinely at one hospital and occasionally at one other hospital in Nairobi. We are also now performing coil or chemical embolization of arterio-venous malformations in hepatic, renal or colorectal tumours. Plans are underway to have cardiac catheterisation facilities at two more hospitals in the near future.

The practice of balloon angioplasty and coronary stenting has expanded exponentially over the years and has reduced the number of patients with coronary artery disease undergoing coronary artery bypass surgery (CABG). Coronary by-pass surgery is the traditional treatment for 
obstructed coronary arteries since 1968 . Overtime, lesions not previously amenable to percutaneous intervention have become treatable due to better equipment and refined techniques(7). However, some patients still undergo bypass surgery particularly those with multivessel coronary artery disease and most left main coronary artery stenosis, among others.

Treatment of atheroscelerotic coronary and peripheral vascular artery disease by percutaneous intervention is the major indication for intervention worldwide today. This is due to the high prevalence of coronary artery disease in the developed world and the emerging high prevalence in the developing world.

Studies comparing single vessel coronary obstructions treated with medical therapy with patients undergoing balloon angioplasty show that angioplasty patients enjoy improved exercise capacity, greater freedom from angina and improved quality of life than those on medical therapy(8). Use of stents in angioplasty patients has increased the benefits even more(9). Stents also have dramatically reduced intraprocedural complications and made the need for emergency coronary artery bypass during procedure a rare occurrence. A meta analysis of eight studies comparing coronary artery by-pass grafting (CABG) with PTCA/ stenting showed that CABG offered no advantage in mortality or non-fatal myocardial infarction over PTCA/ stenting in three to five years. However, PTCA/stenting patients experienced higher need for repeat revascularisation due to restenosis of treated lesions(10). More comfort and less procedure morbidity associated with PTCA/stenting may somewhat offset the higher need for repeat revascularisation compared to $\mathrm{CABG}$.

Balloon valvuloplasty for congenital and acquired valvular stenosis has become standard therapy for selected patients. The first reports involving balloon dilatation of congenital pulmonary valve stenosis were made in 1982(11). This was followed later in the same year by the introduction of the Inoue technique for treating rheumatic mitral valvular stenosis by Inoule K. Owaki in Japan(12). Apart from the Inoue technique, which still enjoys the most popular use worldwide, other techniques include the double balloon technique and its modification, the multi-track technique which was developed by Dr. Phillip Bonhoeffer. Dr. Bonhoeffer is co-author of a study reported in this edition of the journal. Dr. Bonhoeffer must be given recognition for the introduction of balloon valvular intervention in Kenya from the early nineties, both in the pulmonary and mitral valvular position. He has patiently taught a good number of "third generation" Kenyan cardiologists during his many return visits from Europe in the last 10 years, some whom now stand on their own in performing valvular interventions. Alain Cribier of Rouen, France has recently introduced metallic commissurotomy, which uses a device similar to the Tubbs dilator used by surgeons to treat mitral stenosis. The advantage of this metallic valvulotome is that it can be re-sterilised and re-used many times, hence reducing the cost in developing countries . Currently, the multi-track and the Inoue techniques are the ones in common use in Kenya.

Randomised trials comparing mitral balloon valvuloplasty with standard surgical procedures of open or closed commissurotomy have demonstrated equivalent outcome. However, patients treated with the percutaneous technique have reduced procedural morbidity and mortality and a much shorter stay in hospital, and return to work early(14).

Valvular interventions have up to now mainly involved treatment of valvular stenosis. Percutaneous valve replacement has previously defied interventional techniques. However Phillip Bonhoeffer et al(15) have recently reported percutaneous implantation of artificial valves in children with right ventricle to pulmonary artery prosthetic conduits. Alain Cribier et al(16)have also reported percutaneous replacement of a stenotic calcific aortic valve in a patient with cardiogenic shock and inoperable by traditional surgery. These initial successes herald a new era of percutaneous valve replacement. However the era is still in its infancy.

Trans-catheter device closure of secundum atrial septal defects is standard practice in some centres. Patent foramina ovale for patients experiencing paradoxical embolism are also treated in the same way. Patent ductus arteriosus patients are treated with coil embolisation or occluder devices(18).

Symptomatic patients with left ventricular outflow tract obstruction from hypertrophic cardiomyopathy, who are refractory to medical therapy and who previously would undergo surgical myotomy-myomectomy can now undergo trans-catheter septal ablation. Controlled infusion of absolute alcohol to the septal artery branch supplying the hypertrophied septum is done and patients experience symptomatic relief(19).

In this edition of the Journal the study by Yonga and Bohnhoeffer on treatment of juvenile rheumatic mitral valve stenosis using the multitrack technique(20) and the images on coronary intervention showing local advances in this area indicate that cardiology continues to grow despite many challenges that have faced this and other medical specialties in the middle of Africa. The major challenge is to continuously strive to bring down costs of interventional procedures so as to extend the benefits to more patients in this low-income region. Training of more cardiologists, nurses and technicians, acquisition of adequate equipment and consumables are other issues that require the attention of those concerned. Properly planned, percutaneous interventions can reduce costs and therefore increase access to medical services. However, we should not as we enter into these highly technological areas forget that the foremost duty is to practice preventive medicine as this is the most affordable of the available choices. Efforts to prevent rheumatic fever should be promoted. Reduction of risk factors for atherescelerotic vascular diseases in the communities would stem the tide we are seeing now and even the lager one predicted in our region.

R. Mathenge, MBChB, MMed (Int. Med), Cardiology (USA), Interventional Cardiology (USA), Consultant Physician and heart specialist, P.O. Box 2665-0200, City square, Nairobi, Kenya. 


\section{REFERENCES}

1. Forssman, W. Die Sondierung des rechten Herzens: Klin Woehenschr. 1929; 8:2085.

2. Seldinger, S.I. Catheter replacement of the needle in percutaneous arteriography: a new technique: Acta Radial. 1953; 39:368

3. Sones, F.M Jr. Shirey, E.K., Prondfit, W.L. and Westcott, R.N. Cine - coronary arteriography. Circulation. 1959; 20:773.

4. Dotter, C.T., and Judkins, M.P. Transluminal treatment of arteriosclerotic obstructions: Description of a new technique and preliminary report of its application. Circulation. 1964; 30:654.

5. Gruentzig, A.R, Senning, A. and Siegenthaler, W.E. Non operative dilatation of coronary artery stenosis: Percutaneous transluminal coronary angioplasty. N. Engl J. Med. 1969; 301:61.

6. Sigwart, U., Puel, J. Mirkovitch, V. et al. Intravascular stents to prevent occlusion and restenosis after angioplasty. N. Eng J Med. 1987; 316:701-706.

7. S. Windecker, W. et al. on behalf of the working group Coronary Circulation of the European society of cardiology. Euro Heart J. 1999; 20:484-495.

8. Parisi, A.F, Folland, E.D, and Hartigan, P. The Veteran Affairs ACE Investigators: A comparison of angioplasty with medical therapy in the treatment of single vessel disease. N.Eng. J. Med. 1992; 326:10

9. Serruys, P., W. de Jaegere, P. Kiemeneij, F.et al. A comparison of balloon expandable stent implantation with angioplasty in patients with coronary artery disease. N. Engl J. Med. 1994; 331:489.

10. Pocock, S., J., Hernderson, RA, Richards, A.F et al. Meta analysis of randomized trials comparing coronary angioplasty with bypass surgery. Lancet. 1995; 346:1185.
11. Kan, J.S., White R.I.J., Mitchell, S.E. and Gardener, T.J. Percutaneous balloon valvuloplasty: a new method for treating congenital pulmonary valve stenosis. N. Eng. J. Med. 1982; 307:540-542.

12. Inoue, K. Owaki, T. and Nakamura, T. Clinical application of transvenous mitral commissurotomy by a new balloon catheter. J. Thorac. cardiovasc surg.1984; 87:394-402.

13. Cribier, A., Einaninoff, H. Koning, R. et al. Percutaneous mechanical mitral commissurotomy with a newly designed metallic valvulotome. Circulation. 1999; 99:793-799.

14. Reyes, V.P., Soma, Raju, B. Wynne, J. et al. Percutaneous balloon valvuloplasty compared with open surgical commissurotomy for mitral stenosis. N. Engl. J. Med. 1994; 331:961-967.

15. Bonhoeffer, P., Boudjeniline, Y., Saliba, Z. et al. Percutaneous replacement of pulmonary valves in a right ventricle to pulmonary artery prosthetic conduit with valve dysfunction. Lancet. 2000; 350:1403-1405.

16. Cribier, A. Einaninoff H. et al. Percutaneous transcatheter implantation of an aortic valve prosthesis for calcific aortic stenosis. Circulation. 2002; 108:3006-3008.

17. Thanopoulos, B.D., Papadopoulos, G.S., Vekiou A., et al. Closure of atrial septal defects with the amplatzer occlusion device: Preliminary results. J. Amer Coll Cardiol. 1998; 315:111-116.

18. Porstmann, W., Wierny, L., Warnke, H. et al. Catheter closure of patent ductus arteriosus: 62 cases treated without thoracotomy. Radial clin. North Am. 1971; 9:203-218.

19 Sigwart, U. Non surgical myocardial reduction for hypertrophic obstructive cardiomyopathy, Lancet. 1995; 346:211-214.

20. Yonga, G.O and Bonhoeffer P. Percutaneous transvenous mitral commissurotomy in juvenile mitral stenosis. E. Afr. Med. J. 2003; 80:172-174. 